\title{
Fatty acid composition of Turbatrix aceti and its use in feeding regimes of Coregonus maraena (Bloch, 1779): is it really a suitable alternative to Artemia nauplii?
}

\author{
By M. Hundt ${ }^{1}$, J. Brüggemann², B. Grote ${ }^{3}$, A. A. Bischoff ${ }^{4}$, D. Martin-Creuzburg ${ }^{5}$, R. Gergs ${ }^{1}$ and B. H. Buck ${ }^{3,6}$ \\ ${ }^{1}$ Institute for Environmental Sciences, University of Koblenz-Landau, Landau, Germany; ${ }^{2}$ Institute for Marine Resources, \\ Bremerhaven, Germany; ${ }^{3}$ Alfred Wegener Institute Helmholtz Center for Polar and Marine Research, Bremerhaven, Germany; \\ ${ }^{4}$ Aquaculture and Sea-Ranching, Faculty of Agricultural and Environmental Science, University of Rostock, Rostock, Germany; \\ ${ }^{5}$ Limnological Institute, University of Constance, Konstanz, Germany; ${ }^{6}$ University of Applied Sciences, Bremerhaven, Germany
}

\section{Summary}

By incorporating the free-swimming nematode Turbatrix aceti into early feeding regimes of the European whitefish Coregonus maraena, the suitability of this nematode species was investigated as an alternative to Artemia nauplii. During a 14-day feeding trial in a total of 25 aquaria each $1.7 \mathrm{~L}$ (each treatment $\mathrm{n}=5$, 255 larvae/tank) $T$. aceti was used either as the sole live food or in combination with Artemia nauplii or microdiet to determine the effect of $T$. aceti on growth performance and survival rate of $C$. maraena. By analysing the fatty acid composition of $T$. aceti prior to and after enrichment with INVE spresso ${ }^{\circledR}$ it was investigated whether the amount of n3-polyunsaturated fatty acids (n3-PUFA) in T. aceti could be further enhanced. Supplementation of Artemia nauplii with $T$. aceti increased growth significantly within the first 5 days of rearing in comparison to the non-supplemented food treatments $(14.39 \pm 0.15 \mathrm{~mm}$ compared to $13.44 \pm$ $0.18 \mathrm{~mm}$; mean $\pm \mathrm{SE}$ ). However, growth and survival of juvenile C. maraena on nematode-supplemented Artemia nauplii did not differ significantly from non-supplemented Artemia nauplii at the end of the 14-day rearing period (15.22 \pm $0.15 \mathrm{~mm}$ compared to $14.86 \pm 0.24 \mathrm{~mm}$ ). All feeding treatments containing Artemia nauplii showed significantly higher growth and lower mortality at the end of the experiment in comparison to diets containing only the microdiet or $T$. aceti or a combination thereof. The overall low performance of $T$. aceti alone can most likely be explained by an insufficient capacity of $C$. maraena to digest this nematode species efficiently. Enrichment with INVE spresso ${ }^{\circledR}$ successfully increased the proportion of DHA in the $T$. aceti tissue. The results reveal that $T$. aceti cannot be considered a full alternative to Artemia nauplii, at least not in the rearing of $C$. maraena, but might be a useful vector of essential fatty acids within the early rearing period of this and potentially other fish species when provided as live food along with Artemia nauplii.

\section{Introduction}

Live food organisms in aquaculture are currently limited to relatively few species, most prominently the brine shrimp
Artemia salina, and rotifers such as Brachionus sp. (Lavens and Sorgeloos, 1996). Artemia nauplii account for approximately $40 \%$ of the total amount of live food in aquaculture and are particularly convenient in hatchery operations as they can be stored over long time periods and are readily available when needed (Lavens and Sorgeloos, 2000). Due to the rapidly growing demand of hatcheries for live food organisms, the search for non-Artemia alternatives is increasing (Sorgeloos et al., 2001).

Several nematodes were suggested recently as cost-effective alternatives to fish- and crustacean larvae (Brüggemann, 2012; Weber and Traunsburger, 2014). Nematodes have been shown to be especially successful when used in combination with inert artificial diets as co-feeding regimes (Kahan, 1980). Particularly the use of the free-living nematode Panagrellus redivivus has been shown to result in high survival and growth of shrimp larvae and carp species, similar to conventional live food organisms such as Artemia nauplii (Rottmann et al., 1991; Kumlu et al., 1998; Focken et al., 2006; Brüggemann, 2012). Other free-living nematode species, such as Caenorhabditis elegans, C. briggsae and T. aceti, have been used in the culture of adult fish (Hofsten et al., 1983), but their suitability as live food to rear fish larvae has been poorly studied (Brüggemann, 2012). In particular, the free swimming nematode Turbatrix aceti, used for years as fish feed in ornamental fish culture (Hofsten et al., 1983), must be considered as an interesting candidate for feeding of larval fish. T. aceti is easy to culture in high densities and with a low risk of contamination by pathogenic microorganisms due to the natural antibiotic properties of the growth medium (Buck et al., in press). Contrary to many other free-living nematode species, $T$. acet $i$ is able to swim actively in the water column (Brüggemann, 2012), which can increase its availability to pelagic fish larvae and limit the amount of live food necessary for feeding. More importantly, $T$. aceti possess the ability to produce polyunsaturated fatty acids (PUFA) de novo (Rothstein and Götz, 1968) and therefore might be suitable to overcome nutritional deficiencies commonly found in Artemia nauplii (Lavens et al., 1989). Several authors have demonstrated the value of n3-PUFA enrichment strategies: docosahexaenoic acid 
(DHA) and eicosapentaenoic acid (EPA) in particular have been shown to enhance growth and survival of various fish larvae during the production process (Gapasin et al., 1998; Noori et al., 2011b).

Accordingly, growth, survival and general condition of the European whitefish Coregonus maraena have shown significant improvement on artificial diets containing more than $0.5 \%$ n-3 PUFA (Watanabe et al., 1989). The goal of this project was to investigate the fatty acid composition of T. aceti before and after enrichment with commercial PUFA solution and to evaluate the general suitability of this nematode species as a solitary live food or in co-feeding regimes during the early rearing period of C. maraena.

\section{Materials and methods}

Culture of Turbatrix aceti and fatty acid supplementation

The nematode T. aceti was grown according to Buck et al. (in press) on a $50: 50$ solution of apple cider and water added to $25 \mathrm{~g} \mathrm{~L}^{-1}$ peptone at approximately $20^{\circ} \mathrm{C}$ under gentle aeration in two 5-L plastic bottles at xenic conditions. Prior to feeding, Artemia nauplii and nematodes were harvested and their respective densities (ind. $\mathrm{ml}^{-1}$ ) assessed three times under a stereomicroscope and a counting chamber in $0.1 \mathrm{ml}$ water to calculate the daily feeding treatments. For PUFA enrichment, harvested nematodes were transferred into a $50 \mathrm{ml} \mathrm{PE}$ tube filled with tap water and subsequently enriched with Selco S.presso ${ }^{\circledR}$ (INVE-Aquaculture) according to the producer's instructions: $1 \mathrm{~g} \mathrm{~L}^{-1}$ of the emulsion was added to the nematodes at $\mathrm{T}_{0}$ and $\mathrm{T}_{12}$ and harvested after $24 \mathrm{~h}$. The nematodes were then rinsed through a $20 \mu \mathrm{m}$ gauze and stored frozen at $-80^{\circ} \mathrm{C}$ for subsequent fatty acid analyses. Simultaneously, non-enriched nematodes, Minipro ${ }^{\mathrm{TM}}$ and Artemia were frozen at $-80^{\circ} \mathrm{C}$ until analysis.

\section{Experimental design}

Larvae of C. maraena were obtained at 2 days post hatch (dph) from a Schleswig-Holstein fish hatchery (Fischbrutanstalt Altmühlendorf, Schleswig-Holstein, Germany) and transferred in oxygen filled plastic bags to the Centre for Aquaculture Research (Zentrum für Aquakulturforschung- ZAF) in Bremerhaven, Germany.

After arrival the larvae were transferred into independent static $1.7 \mathrm{~L}$ aquaria (five replicates per treatment) with a stocking density of 150 larvae $\mathrm{L}^{-1}$. Larvae were reared at $17^{\circ} \mathrm{C}$ under natural photoperiod conditions (11 h : $13 \mathrm{~h}$ light : dark regime) and continuously aerated. Prior to the experiment, larvae at day-3 post hatch were counted by means of a digital camera system (Canon 550 D) and the number of larvae was stocked up to 255 larvae/tank, where necessary. Fish larvae were exposed to five different feeding regimes, including Microdiet Minipro $^{\mathrm{TM}}$ (Maripro AS), Artemia salina as well as $T$. aceti, either as exclusive feed or in combination with the other two feed sources over a 16-day period (Table 1). At least $2 / 3$ of the culture water $(>1 \mathrm{~L})$ was exchanged manually twice per day, once in the morning before feeding and once in the evening from a preheated tank.

Cysts of A. salina (Sanders Brine Shrimp Company, Ogden, UT) were decapsulated and hatched in cylindro-conical polyethylene containers according to Lavens and Sorgeloos (1996). Feeding of fish was performed manually on a daily basis at $9: 00$ in the morning. At 8 and 16 days post hatch a minimum of five larvae from each tank were sampled (Canon EOS 550D) for determination of total body length using the software package IRFANVIEW (Version 4.30). Larvae were counted $8 \mathrm{dph}$ and after the termination of the experiment at $17 \mathrm{dph}$ using digital photography to calculate the mean survival per treatment.

\section{Fatty acid analysis}

Samples of all feed sources (Artemia nauplii, Minipro ${ }^{\mathrm{TM}}$, $T$. aceti, $T$. aceti + S.presso $\left.{ }^{\circledR}\right)$ were freeze-dried and ground. Lipids were extracted twice from the different food items (1-10 mg freeze-dried material) using a mixture of dichloromethane/methanol $(2: 1, \mathrm{v} / \mathrm{v})$. For the analysis of fatty acids, the cell-free extracts were dried under a stream of nitrogen and esterified with $3 \mathrm{~mol} \mathrm{~L}^{-1}$ methanolic $\mathrm{HCl}$ $\left(60^{\circ} \mathrm{C}, 20 \mathrm{~min}\right)$. Next, fatty acid methyl esters (FAMEs) were partitioned into iso-hexane, dried under a stream of nitrogen, and resuspended in a volume of $50 \mu \mathrm{l}$ iso-hexane. Lipids were then analyzed by gas chromatography on an HP 6890 GC (Agilent Technologies) equipped with a flame ionization detector and a DB-225 capillary column (J and W Scientific). Details of GC configurations are given elsewhere (MartinCreuzburg et al., 2010). Fatty acids were quantified by comparison to internal standards $(\mathrm{C} 17: 0$ and $\mathrm{C} 23: 0$ methyl esters); the quantification limit was $20 \mathrm{ng}$ of fatty acid. Fatty acids were identified by their retention times and their mass spectra, which were recorded with a gas chromatograph-mass spectrometer (Agilent Technologies, 5975C) equipped with a fused silica capillary column (DB-225MS, J and W Scientific). Mass spectra were recorded between 50 and 600

Table 1

Description of five different feeding regimes used in C. maraena 14-day feeding trial

\begin{tabular}{|c|c|c|c|}
\hline \multirow[b]{2}{*}{ Food treatment } & \multicolumn{3}{|l|}{ Composition } \\
\hline & Turbatrix aceti & Artemia nauplii & Minipro Microdiet \\
\hline A & - & 5 Ind. $\mathrm{ml}^{-1} \mathrm{day}^{-1}$ & - \\
\hline $\mathrm{A}+\mathrm{T}$ & 10 Ind. $\mathrm{ml}^{-1}$ day $^{-1}$ & 3 Ind. $\mathrm{ml}^{-1} \mathrm{day}^{-1}$ & - \\
\hline M & - & - & $0.1 \mathrm{mg} \mathrm{ml}^{-1}$ day $^{-1}$ \\
\hline $\mathrm{M}+\mathrm{T}$ & 10 Ind. $\mathrm{ml}^{-1}$ day $^{-1}$ & - & $0.05 \mathrm{mg} \mathrm{ml}^{-1} \mathrm{day}^{-1}$ \\
\hline $\mathrm{T}$ & 20 Ind. $\mathrm{ml}^{-1}$ day $^{-1}$ & - & - \\
\hline
\end{tabular}


Dalton in the electron impact ionization mode and compared to mass spectra of reference substances purchased from Sigma-Aldrich.

\section{Statistical analysis}

Analysis of variance (ANOVA) was applied to compare average total length of $C$. maraena larvae fed on different feeding regimes after a rearing period of 5 and 13 days ( 8 and $16 \mathrm{dph}$ ) as well as for the fatty acid analysis. Data were logtransformed and checked for normality of residuals (Shapiro-Wilk's test) and equality of variance (Levene's test). Fatty acid data were arcsin transformed to ensure normal distribution and tested for equality of variance (Levene's test). Generalized linear modelling (GLM, family = binomial) was applied to test for significant differences in overall survival between the treatments at 8 and $17 \mathrm{dph}$. Post-hoc comparisons between treatments were performed for all measured variables according to the Tukey-Kramer method. All statistical tests were conducted using R Version 2.13.0 (R Development Core Team, 2013) at a significance niveau of $\alpha=0.05$.

\section{Results}

\section{Fatty acid composition of the nematodes}

Nematodes contained significantly higher levels of total fatty acids than the MD Minipro ${ }^{\mathrm{TM}}$ and Artemia nauplii (ANOvA, $\mathrm{P}<0.005$; Table 2). Both groups of nematodes contained approximately twice the amount of fatty acids found in Artemia nauplii. Although Artemia nauplii contained significantly higher amounts of n-3 PUFA compared to nematodes (ANOVA, $\mathrm{P}<0.007$; Table 2), the relative contribution of EPA was significantly lower than in T. aceti (ANOvA, $\mathrm{P}<0.001$; Table 2) and DHA was completely absent in Artemia. Non-enriched specimens of $T$. aceti contained $0.8 \pm 0.6 \%$ DHA and $18.3 \pm 2.1 \%$ EPA prior to enrichment. After enrichment, DHA concentrations were 19 -fold higher $(15.0 \pm 2.4 \%)$ in $T$. aceti and thus significantly higher than in any other food item (anOva, $\mathrm{P}<0.001$; Table 2).

\section{Survival and growth of $C$. maraena larvae}

Larvae in all treatments were observed to actively feed on T. aceti, Artemia nauplii and MD. Survival rates of $C$. maraena

Table 2

Fatty acid composition of Artemia sp., Minipro ${ }^{\mathrm{TM}}$ microdiet and T. aceti prior to enrichment and after enrichment with commercial PUFA solution $(T$. aceti + ). All values in percentage of total fatty acids unless otherwise stated

\begin{tabular}{|c|c|c|c|c|}
\hline & Artemia sp. & Minipro $^{\mathrm{TM}}$ & T. aceti & T. aceti+ \\
\hline FA total $\left(\mu \mathrm{g} \mathrm{FA} \mathrm{mg}^{-1} \mathrm{DW}\right)$ & $54.9 \pm 1.5^{\mathrm{a}}$ & $81.4 \pm 3.7^{b}$ & $111.1 \pm 19.0^{\mathrm{c}}$ & $104.1 \pm 7.5^{\mathrm{c}}$ \\
\hline $14: 0$ & $1.3 \pm 0.1^{\mathrm{a}}$ & $5.0 \pm 0.2^{\mathrm{b}}$ & $2.1 \pm 0.3^{\mathrm{c}}$ & $3.1 \pm 0.4^{\mathrm{c}}$ \\
\hline $15: 0$ & nd & $0.4 \pm 0.0^{\mathrm{a}}$ & nd & $0.3 \pm 0.0^{\mathrm{b}}$ \\
\hline $16: 0$ & $17.0 \pm 0.9^{\mathrm{a}}$ & $20.0 \pm 0.7^{b}$ & $4.8 \pm 1.1^{\mathrm{c}}$ & $11.7 \pm 1.1^{\mathrm{d}}$ \\
\hline $18: 0$ & $8.5 \pm 0.3^{\mathrm{a}}$ & $2.7 \pm 0.1^{\mathrm{b}}$ & $9.0 \pm 2.3^{\mathrm{a}}$ & $5.6 \pm 0.2^{\mathrm{c}}$ \\
\hline $20: 0$ & $0.2 \pm 0.4^{\mathrm{a}}$ & $0.6 \pm 0.0^{\mathrm{a}}$ & $0.6 \pm 0.1^{\mathrm{a}}$ & $0.5 \pm 0.0^{\mathrm{a}}$ \\
\hline $21: 0$ & $1.0 \pm 0.2^{\mathrm{a}}$ & nd & nd & nd \\
\hline $22: 0$ & $0.5 \pm 0.1^{\mathrm{a}}$ & $1.8 \pm 0.2^{\mathrm{b}}$ & nd & $0.4 \pm 0^{\mathrm{a}}$ \\
\hline SAFA total & $28.5 \pm 0.8^{\mathrm{a}}$ & $30.5 \pm 1.3^{\mathrm{b}}$ & $16.5 \pm 3.4^{\mathrm{c}}$ & $21.6 \pm 1.7^{\mathrm{d}}$ \\
\hline $16: 1 n-7$ & $2.5 \pm 0.1^{\mathrm{a}}$ & $1.9 \pm 0.1^{\mathrm{ab}}$ & $2.5 \pm 0.6^{\mathrm{a}}$ & $3.2 \pm 0.3^{\mathrm{ac}}$ \\
\hline $17: 1 n-7$ & $1.0 \pm 0.1^{\mathrm{a}}$ & $0.5 \pm 0.0^{\mathrm{b}}$ & nd & $0.3 \pm 0.0^{\mathrm{c}}$ \\
\hline $18: 1 n-12 / n-9$ & $23.9 \pm 0.9^{\mathrm{a}}$ & $10.6 \pm 0.7^{\mathrm{b}}$ & $27.5 \pm 5.0^{\mathrm{c}}$ & $11.9 \pm 1.2^{\mathrm{d}}$ \\
\hline $18: 1 n-7$ & $6.3 \pm 0.5^{\mathrm{a}}$ & $2.1 \pm 0.1^{\mathrm{b}}$ & $0.7 \pm 0.1^{\mathrm{c}}$ & $4.9 \pm 0.3^{\mathrm{d}}$ \\
\hline $20: \ln -9$ & $1.2 \pm 0.1^{\mathrm{a}}$ & $2.6 \pm 0.3^{\mathrm{b}}$ & $0.4 \pm 0.1^{\mathrm{c}}$ & $0.4 \pm 0.0^{\mathrm{c}}$ \\
\hline $20: 1 n-7$ & $0.6 \pm 0.1^{\mathrm{a}}$ & $0.0 \pm 0.0^{\mathrm{b}}$ & $3.3 \pm 0.7^{\mathrm{c}}$ & $1.1 \pm 0.1^{\mathrm{d}}$ \\
\hline $22: \ln -9$ & nd & $0.3 \pm 0.0^{\mathrm{a}}$ & $0.2 \pm 0.0^{\mathrm{a}}$ & nd \\
\hline $24: 1 n-9$ & $0.0 \pm 0.0^{\mathrm{a}}$ & $0.3 \pm 0.0^{\mathrm{b}}$ & $0.3 \pm 0.1^{\mathrm{b}}$ & $0.2 \pm 0.0^{\mathrm{b}}$ \\
\hline MUFA total & $35.5 \pm 1.4^{\mathrm{a}}$ & $18.2 \pm 1.2^{\mathrm{b}}$ & $35.0 \pm 6.1^{\mathrm{a}}$ & $22.0 \pm 2.0^{\mathrm{c}}$ \\
\hline $18: 2 \mathrm{n}-6$ & $4.1 \pm 0.2^{\mathrm{a}}$ & $20.9 \pm 1.1^{\mathrm{b}}$ & $12.2 \pm 2.3^{\mathrm{c}}$ & $17.3 \pm 1.4^{\mathrm{d}}$ \\
\hline $18: 3 n-6$ & $0.7 \pm 0.0^{\mathrm{a}}$ & nd & $1.4 \pm 0.2^{\mathrm{b}}$ & $0.8 \pm 0.1^{\mathrm{a}}$ \\
\hline $20: 2 n-6$ & $0.1 \pm 0.3^{\mathrm{a}}$ & nd & $1.0 \pm 0.3^{\mathrm{b}}$ & $0.9 \pm 0.1^{\mathrm{b}}$ \\
\hline $20: 3 n-6$ & nd & $3.7 \pm 0.3^{\mathrm{a}}$ & $5.0 \pm 0.9^{\mathrm{b}}$ & $2.2 \pm 0.1^{\mathrm{c}}$ \\
\hline $20: 4 n-6$ & $0.5 \pm 0.0^{\mathrm{a}}$ & $1.1 \pm 0.1^{\mathrm{b}}$ & $2.4 \pm 0.6^{\mathrm{c}}$ & $1.0 \pm 0.1^{\mathrm{b}}$ \\
\hline n-6 PUFA & $5.5 \pm 0.5^{\mathrm{a}}$ & $25.7 \pm 1.4^{\mathrm{b}}$ & $22.0 \pm 4.1^{\mathrm{c}}$ & $22.3 \pm 1.8^{\mathrm{c}}$ \\
\hline $18: 3 n-3$ & $24.1 \pm 1.2^{\mathrm{a}}$ & $2.8 \pm 0.1^{\mathrm{b}}$ & $0.7 \pm 0.2^{\mathrm{c}}$ & $2.9 \pm 0.2^{\mathrm{b}}$ \\
\hline $18: 4 n-3$ & $4.1 \pm 0.2^{\mathrm{a}}$ & $1.8 \pm 0.1^{\mathrm{b}}$ & $0.5 \pm 0.2^{\mathrm{c}}$ & $0.4 \pm 0.0^{\mathrm{c}}$ \\
\hline $20: 3 n-3$ & nd & nd & $0.4 \pm 0.1^{\mathrm{a}}$ & $0.4 \pm 0.0^{\mathrm{a}}$ \\
\hline $20: 4 n-3$ & $1.1 \pm 0.1^{\mathrm{a}}$ & $0.6 \pm 0.0^{\mathrm{b}}$ & $5.9 \pm 1.5^{\mathrm{c}}$ & $2.6 \pm 0.1^{\mathrm{d}}$ \\
\hline 20:5n-3 EPA & $1.3 \pm 0.1^{\mathrm{a}}$ & $7.4 \pm 0.5^{\mathrm{b}}$ & $18.3 \pm 2.1^{\mathrm{c}}$ & $12.2 \pm 0.7^{\mathrm{d}}$ \\
\hline $22: 5 n-3$ & nd & $0.5 \pm 0.0^{\mathrm{a}}$ & nd & $0.7 \pm 0.1^{\mathrm{b}}$ \\
\hline $22: 6 n-3$ DHA & nd & $12.4 \pm 0.1^{\mathrm{a}}$ & $0.8 \pm 0.6^{\mathrm{b}}$ & $15.0 \pm 2.4^{\mathrm{a}}$ \\
\hline n-3 PUFA & $30.5 \pm 1.6^{\mathrm{a}}$ & $25.5 \pm 0.8^{\mathrm{b}}$ & $26.6 \pm 3.6^{\mathrm{b}}$ & $34.1 \pm 3.6^{\mathrm{c}}$ \\
\hline PUFA total & $36.0 \pm 2.1^{\mathrm{a}}$ & $51.2 \pm 2.2^{\mathrm{b}}$ & $48.6 \pm 7.7^{\mathrm{c}}$ & $56.4 \pm 5.2^{\mathrm{d}}$ \\
\hline
\end{tabular}

nd, not detected; FA, Fatty acids; SAFA, saturated fatty acids; MUFA, monounsaturated fatty acids; PUFA, polyunsaturated fatty acids; n3-PUFA total, total amount of Omega n-3 polyunsaturated fatty acids; n-6-PUFA total, total amount of Omega n-6 polyunsaturated fatty acids; EPA, Eicosapentaenoic acid; DHA, Docosahexaenoic acid.

Values within each row with different superscript letter denote significance $(\mathrm{P}<0.05 ; \mathrm{n}=3)$. 
larvae reared on food treatments containing Artemia (A and $\mathrm{A}+\mathrm{T})$ were significantly higher $(>60 \%)$ than in any other treatment (GLM, P < 0.0002) at the end of the experiment (Fig. 1a), while at 8 dph only feeding regimes $\mathrm{M}$ and $\mathrm{T}$ were significantly different from each other (GLM, P < 0.04). Lowest survival was observed in regime $\mathrm{T}(74 \pm 1.5 \%)$, while highest survival was found in treatment $\mathrm{M}(86 \pm 2.7 \%)$ (Fig. 1a).

Fish larvae growth was generally higher in treatments containing Artemia nauplii compared to all other treatments (Fig. 1b). At 8 dph fish fed the combination of Artemia sp. and $T$. aceti (Treatment $\mathrm{A}+\mathrm{T}$ ) were significantly larger than fish from any other treatment (ANOVA, $\mathrm{P}<0.002$ ). At 16 dph highest growth in length was found in treatments $\mathrm{A}$ and $\mathrm{A}+\mathrm{T}$ (ANOvA, $\mathrm{P}<0.001$ ).

\section{Discussion}

\section{Survival and growth of $C$. maraena larvae}

The nematode T. aceti was found to contain higher levels of EPA and DHA compared to Artemia nauplii, which transferred to a higher growth rate of $C$. maraena larvae in combination with Artemia nauplii at day 8 post hatch, but not to higher survival or better growth at the end of the experiment
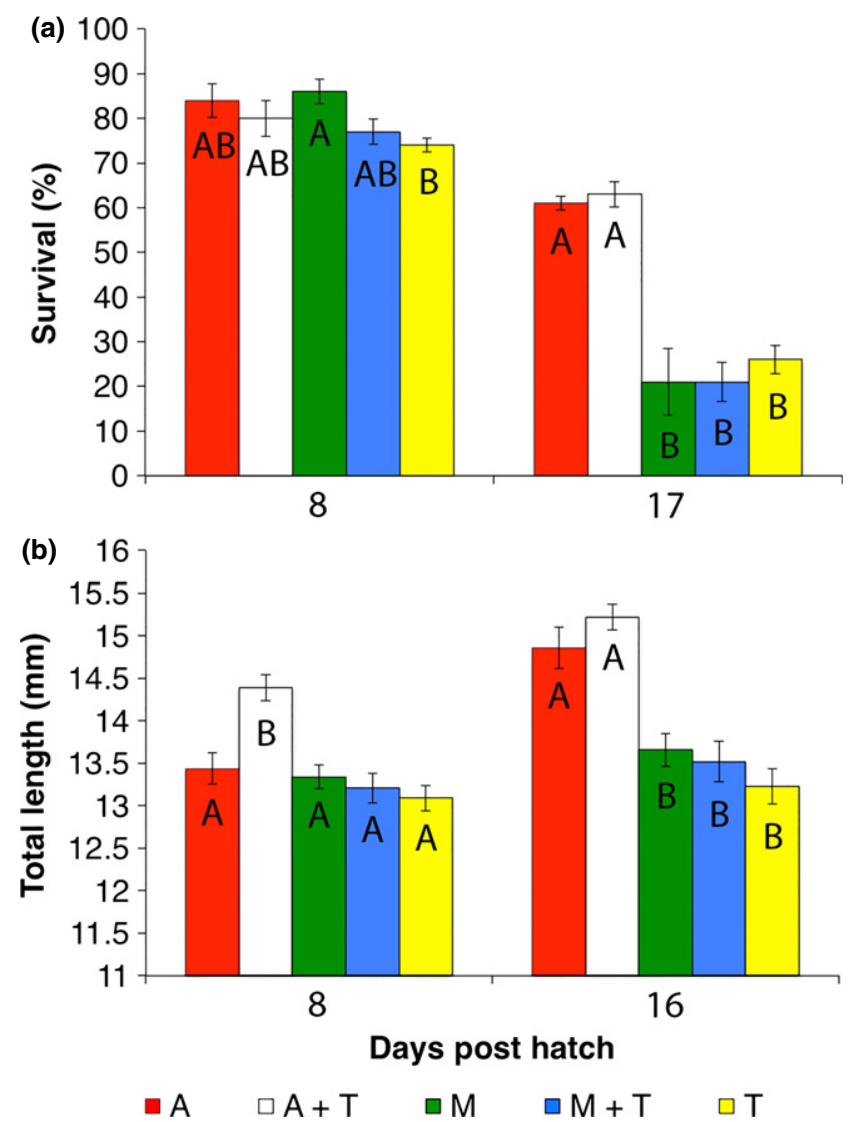

Fig. 1. (a) Relative survival (\%) and (b) length-increment ( $\mathrm{mm}$ ) of $C$. maraena during a 14-day feeding trial. Five different feeding regimes in five replicates were investigated (A: Artemia sp., A+T: Artemia sp. + T. aceti, M: microdiet, M+T: microdiet + T. aceti, T: T. acet $;$; see Table 1 for detailed description of each feeding regime). Significant differences according to the Tukey-Kramer method denoted by capital letters. All values displayed as mean \pm standard error. For determination of length a minimum of five larvae per replicate was analysed
(Fig. 1). This finding suggests that C. maraena larvae benefit from increased levels of n-3 PUFA during first feeding, as also found for juvenile C. maraena of approx. 3 months of age (Watanabe et al., 1989). Furthermore, results reveal that $T$. aceti seem to be beneficial especially within the earliest rearing period of fish larvae due to their relative small size compared to Artemia nauplii, which might facilitate the onset of exogenous feeding in C. maraena. The maximum size of prey is determined mainly by the ability of a given fish larvae to ingest particles of a certain size (Lavens and Sorgeloos, 1996). In contrast, the minimum size is limited by the fact that at some point the energy expenditure for searching, capturing and ingesting is surpassing the energetic gain from this small food item (Lubzens, 1987), suggesting that the larger Artemia nauplii become increasingly available for the growing larvae between 8 and $16 \mathrm{dph}$, while the energetic gain from consumption of nematodes is decreasing. Although C. maraena is principally capable of digesting $T$. aceti, the low survival rate and slow growth in feeding treatments, where $T$. aceti was fed exclusively (T) or in combination with microdiet (M+T) (Fig. 1), indicates that this species is unsuitable in replacing Artemia nauplii as the main food source, but could serve as a potential vector of essential fatty acids in co-feeding regimes. For example, the nematodes may be fed with a gradual transition towards increasingly larger proportions of Artemia, similar to the use of the rotifer Brachionus plicatilis in the aquaculture of marine fish larvae (Conceição et al., 2010).

The low performance of $T$. aceti as a single food source is most likely connected to its impaired digestibility, as already described for other coregonid species fed with nematodes that pass the intestinal tract undigested in large proportions (Schlechtriem et al., 2005). A reduced digestibility of nematodes can partially be explained by the slender elongated body shape and the moving pattern of nematodes, which reduces the gut passage time in comparison to Artemia nauplii (Schlechtriem et al., 2005). However, the main reason is presumably the cuticle of nematodes, which is known to show high resistance against solvents and digestive enzymes (Hofsten et al., 1983; Bird and Bird, 1991; Schlechtriem et al., 2005). That $T$. aceti is permanently living in vinegar an acidic environment - (Ebner et al., 2000), the cuticle of the species might be able to withstand acid-based digestion even longer than that of other free-living nematode species.

\section{Fatty acid composition}

The DHA levels (Table 2) of PUFA-enriched nematodes were more than twice the levels reported for PUFA-enriched Artemia nauplii, whereas the proportional contribution of EPA (Table 2) was comparable to those found in enriched Artemia nauplii (Shields et al., 1999). The measured DHA contribution furthermore surpasses values reported for the free-swimming nematode Panagromlaimus sp., that has been enriched comparably with S.presso ${ }^{\circledR}$ at different concentrations (Honnens et al., 2013). The mean EPA fraction of non-enriched specimens of $T$. aceti found in our study nearly doubles those values reported by Krusberg (1972) and also surpasses the maximum reported amount of EPA for non-enriched 
P. redivivus specimens (Schlechtriem et al., 2004). Therefore, the suitability of $T$. aceti should be investigated with particular regard to marine fish species known to have higher DHA requirements (Tocher, 2010). In larvae of freshwater or anadromous fish a sufficient supply with n-3 PUFA in combination with suitable vitamins can also improve survival in high stress situations, as shown for the two fish species Stizostedion vitreum and Acipenser persicus during exposure to salinity and temperature changes or when facing elevated levels of nitrite and ammonia, situations typically encountered during stocking (Kolkovski et al., 2000; Noori et al., 2011a). Therefore, co-feeding of $T$. aceti can be considered particularly useful in situations where fish larvae are stocked directly after the first feeding period, as is, for example, performed in restocking programmes for the Allis shad (Alosa alosa) in the Rhine River (Klinger, 2011).

\section{Conclusions}

Most likely due to its solid cuticle, $T$. aceti as a solitary feed or in combination with MD cannot match the performance levels provided by Artemia nauplii in the early rearing period of C. maraena. Nevertheless, incorporation of T. aceti into the feeding regime of $C$. maraena in co-feeding with Artemia nauplii enhanced growth significantly within the first 5 days of the rearing period. Therefore, T. aceti might be suitable for improving rearing protocols at least of $C$. maraena as a cost-effective vector of essential fatty acids. Due to the easy production, advantageous fatty acid composition and active swimming ability, the application of $T$. aceti as larval live food should be evaluated for other fish, particularly crustacean species, which have shown the ability to digest nematodes more efficiently than fish at an early developmental stage (Brüggemann, 2012).

\section{Acknowledgements}

The authors thank Albrecht Hahn for providing the larvae. Furthermore, we would like to thank Sabine Strieben and Marcus Thon for their assistance during the experiments. This research was partly funded by the Federal State of Bremen (Germany): The Senate for Environmental Affairs, Construction, Transport and Europe within the funding program “Applied Environmental Research - AUF" (FV 198).

\section{References}

Bird, A. F.; Bird, J., 1991: The Structure of Nematodes. Academic Press, San Diego. ISBN 0-12-099651-0.

Brüggemann, J., 2012: Nematodes as live food in larviculture -a review. J. World Aquac. Soc. 43, 739-763.

Buck, B.; Brüggemann, J.; Hundt, M.; Bischoff, A. A.; Hagen, W., in press: Improving nematode culture techniques and their effects on amino acid profile with considerations on production costs. J. Appl. Ichthyol.

Conceição, L. E. C.; Yúfera, M.; Makridis, P.; Morais, S.; Dinis, M. T., 2010: Live feeds for early stages of fish rearing. Aquac. Res. 41, 613-640.

Ebner, H.; Follmann, H.; Sellmer, S., 2000: Vinegar. In: Ullmann's Encyclopedia of Industrial Chemistry. F. Ullman (Ed.). WileyVCH, Weinheim, pp. 403-418.
Focken, U.; Schlechtriem, C.; von Wuthenau, M.; Garcia-Ortega, A.; Puello-Cruz, A.; Becker, K., 2006: Panagrellus redivivus mass produced on solid media as live food for Litopenaeus vannamei larvae. Aquac. Res. 37, 1429-1436.

Gapasin, R. S. J.; Bombeo, R.; Lavens, P.; Sorgeloos, P.; Nelis, H., 1998: Enrichment of live food with essential fatty acids and vitamin C: effects on milkfish (Chanos chanos) larval performance. Aquaculture 162, 269-286.

Hofsten, A. V.; Kahan, D.; Katznelson, R.; Bar-El, T., 1983: Digestion of free-living nematodes fed to fish. J. Fish Biol. 23, 419-428.

Honnens, H.; Assheuer, T.; Ehlers, R. U., 2013: Enrichment of the nematode Panagrolaimus sp., a potential live food for marine aquaculture, with essential n-3 fatty acids. Aquacult. Int. 22, 399-409.

Kahan, D., 1980: Free living nematodes as a dietary supplement in the rearing of fish fry in hatcheries. Gen. Fish. Counc. Med. Stud. Rev. 57, 67-78.

Klinger, H., 2011: Final Report for the Life-Project LIFE06 NAT/ D/000005: The re-introduction of the Allis shad (Alosa alosa) to the Rhine system. Landesamt fu"r Natur, Umwelt und Verbraucherschutz in NRW (LANUV), Fachbereich 26 Fischereio"kologie.

Kolkovski, S.; Czesny, S.; Yackey, C.; Moreau, R.; Cihla, F.; Mahan, D.; Dabrowski, K., 2000: The effect of vitamins C and E in (n-3) highly unsaturated fatty acids-enriched Artemia nauplii on growth, survival, and stress resistance of fresh water walleye Stizostedion vitreum larvae. Aquac. Nutr. 6, 199-206.

Krusberg, L. R., 1972: Fatty acid composition of Turbatrix aceti and its culture medium. Comp. Biochem. Physiol. B 41, 89-98.

Kumlu, M.; Fletcher, D. J.; Fisher, C. M., 1998: Larval pigmentation, survival and growth of Penaeus indicus fed the nematode Panagrellus redivivus enriched with astaxanthin and various lipids. Aquac. Nutr. 4, 193-200.

Lavens, P.; Sorgeloos, P., (Eds)., 1996: Manual on the Production and use of live food for Aquaculture. FAO Fisheries Technical Paper 361. 295 pp. ISBN 92-5-103934-8.

Lavens, P.; Sorgeloos, P., 2000: The history, present status and prospect of the availability of Artemia cysts for aquaculture. Aquaculture 181, 397-403.

Lavens, P.; Leger, P.; Sorgeloos, P., 1989: Manipulation of the fatty acid profile in Artemia offspring produced in intensive culture systems. In: Aquaculture: a Biotechnology in Progress. N. De Pauw, H. Jaspers, N. Ackenfors and N. Wilkins (Eds). Proceedings of the European Aquaculture Society, Bredene, Belgium, pp. 731-739.

Lubzens, E., 1987: Raising rotifers for use in aquaculture. In: Rotifer Symposium IV. Hydrobiologia. L. May, R. Wallace and A. Herzig (Eds). Dr W. Junk Publishers, Dordrecht, 147, pp. 245255.

Martin-Creuzburg, D.; Wacker, A.; Basen, T., 2010: Interactions between limiting nutrients: consequences for somatic and population growth of Daphnia magna. Limnol. Oceanogr. 55, 25972607.

Noori, F.; Takami, G. A.; Van Speybroeck, M.; Van Stappen, G.; Sorgeloos, P., 2011a: Feeding Acipenser persicus and Huso huso (Acipenseriformes) larvae with Artemia urmiana nauplii enriched with HUFA and vitamin C: II. Effect on tolerance to shock exposure of environmental factors. J. Appl. Ichthyol. 27, 787-795.

Noori, F.; Takami, G. A.; Van Speybroeck, M.; Van Stappen, G.; Shiri-Harzevili, A. R.; Sorgeloos, P., 2011b: Feeding Acipenser persicus and Huso huso larvae with Artemia urmiana nauplii enriched with highly unsaturated fatty acids and vitamin C: effect on growth, survival and fatty acid profile. J. Appl. Ichthyol. 27, 781-786.

R Development Core Team, 2013: R: a language and environment for statistical computing. R Foundation for Statistical Computing, Vienna, Austria.

Rothstein, M.; Götz, P., 1968: Biosynthesis of fatty acids in the free living nematode Turbatrix aceti. Arch. Biochem. Biophys. 126, $131-140$. 
Rottmann, R. W.; Shireman, J. V.; Lincoln, E. P., 1991: Comparison of three live foods and two dry diets for intensive culture of grass carp and bighead carp larvae. Aquaculture 96, 269-280.

Schlechtriem, C.; Tocher, D. R.; Dick, J. R.; Becker, K., 2004 Incorporation and metabolism of fatty acids by desaturation and elongation in the nematode, Panagrellus redivivus. Nematology 6, 783-795.

Schlechtriem, C.; Focken, U.; Becker, K., 2005: Digestion and assimilation of the free-living nematode Panagrellus redivivus fed to first feeding coregonid larvae: evidence from histological and isotopic studies. J. World Aquac. Soc. 36, 24-31.

Shields, R. J.; Bell, J. G.; Luizi, F. S.; Gara, B.; Bromage, N. R.; Sargent, J. R., 1999: Natural copepods are superior to enriched Artemia nauplii as feed for halibut larvae (Hippoglossus hippoglossus) in terms of survival, pigmentation and retinal morphology: relation to dietary essential fatty acids. J. Nutr. 129, 11861194
Sorgeloos, P.; Dhert, P.; Candreva, P., 2001: Use of the brine shrimp, Artemia spp., in marine fish larviculture. Aquaculture 200, 147-159.

Tocher, D. R., 2010: Fatty acid requirements in ontogeny of marine and freshwater fish. Aquacult. Res. 41, 717-732.

Watanabe, T.; Thongrod, S.; Takeuchi, T.; Satoh, S.; Kubota, S. S.; Fujimaki, Y.; Cho, C. Y., 1989: Effect of dietary n-6 and n-3 fatty acids on growth, fatty acid composition and histological changes of white fish Coregonus lavaretus maraena. B. Jpn. Soc. Sci. Fish. 55, 1977-1982. (in Japanese).

Weber, S.; Traunsburger, W., 2014: Consumption and prey size selection of the nematode Caenorhabditis elegans by different juvenile stages of freshwater fish. Nematology 16, 631-641.

Author's address: Matthias Hundt, Institute for Environmental Sciences, University of Koblenz-Landau, Fortrstraße 7, 76829 Landau, Germany.

E-mail: Hundt@uni-landau.de 